\title{
SOBOLEV TYPE MATHEMATICAL MODELS WITH RELATIVELY POSITIVE OPERATORS IN THE SEQUENCE SPACES
}

\author{
N.N. Solovyova, S.A. Zagrebina, G.A. Sviridyuk \\ South Ural State University, Chelyabinsk, Russian Federation \\ E-mail: zargebinasa@susu.ru
}

In the sequence spaces which are analogues of Sobolev function spaces we consider mathematical model whose prototypes are Barenblatt - Zheltov Kochina equation and Hoff equation. One should mention that these equations are degenerate equations or Sobolev type equations. Nonexistence and nonuniqueness of the solutions is the peculiar feature of such equations. Therefore, to find the conditions for positive solution of the equations is a topical research direction. The paper highlights the conditions sufficient for positive solutions in the given mathematical model. The foundation of our research is the theory of the positive semigroups of operators and the theory of degenerate holomorphic groups of operators. As a result of merging of these theories a new theory of degenerate positive holomorphic groups of operators has been obtained. The authors believe that the results of a new theory will find their application in economic and engineering problems.

Keywords: Sobolev sequence spaces; Sobolev type models; degenerate positive holomorphic groups of operators.

\section{Introduction}

The Barenblatt-Zheltov-Kochina equation [1]

$$
(\lambda-\Delta) u_{t}=\alpha \Delta u+f
$$

simulates the pressure dynamics of the fluid filtered in fractured porous media. Besides, the equation (1) simulates processes of moisture transfer in a soils [2] and processes of the solid-to-fluid thermal conductivity in the environment with two temperatures [3]. Note that the required function $u=u(x, t)$ must be nonnegative, that is $u \geq 0$ by physical necessity. The Hoff equation [4]

$$
(\lambda+\Delta) u_{t}=\alpha u+f
$$

simulates the H-beam buckling under the influence of high temperatures. The case is also most interesting when the required function $u=u(x, t)$ is nonnegative.

Consider both equations as special cases of Sobolev type mathematical model such as

$$
L u_{t}=M u+f \text {, }
$$

given in Sobolev sequence spaces

$$
l_{q}^{m}=\left(u=\left\{u_{k}\right\}: \sum_{k=0}^{\infty} \lambda_{k}^{\frac{m q}{2}}\left|u_{k}\right|^{q}<\infty\right), m \in \mathbb{R}, q \in[1,+\infty) .
$$

Here $L=L(\Lambda)$ and $M=M(\Lambda)$ is polynomials with real coefficients, and their degrees satisfy the relation

$$
\operatorname{deg} L \geq \operatorname{deg} M
$$

$\Lambda$ is transfer of the Laplace operator $\Delta$ to spaces $l_{q}^{m}$, a $\left\{\lambda_{k}: \lambda_{k} \in \mathbb{R}_{+}\right\}$is monotonically increasing sequence such as $\lim _{k \rightarrow \infty} \lambda_{k}=+\infty$.

The peculiarities of our approach will be, firstly, the active use of the theory of bounded operators and the degenerate holomorphic groups of operators generated by them [5, ch. 3]. Secondly, we apply the theory of positive groups of operators, defined on Banach lattices [6, ch. 2 and 3], to lay the foundations of the theory of positive degenerate holomorphic groups of operators whose phase spaces are Banach lattices. Thirdly, we consider the concrete mathematical model (3) in Sobolev sequence spaces $l_{q}^{m}, m \in \mathbb{R}, q \in[1,+\infty)$, which can be interpreted as the space of Fourier coefficients of solutions 


\section{Математика}

of initial-boundary value problems for equations of the form (1) or (2). Let us note the difference between our approach and the ideas and methods proposed in [7].

The foundations of the theory of degenerate positive groups of operators theory are laid in the first part of the article, which are generated by relatively positively bounded operators. The degenerate positive holomorphic groups of operators obtained are applied to the study of the Cauchy problem solvability for the homogeneous (that is $f(t) \equiv 0$ ) abstract equation (3). The initial value is taken from the phase space of such an equation. In the second part, the solvability of the Showalter-Sidorov problem [8] for the abstract nonhomogeneous equation (3) was studied. Sufficient conditions are obtained for the existence of a positive solution of this problem. Abstract results are applied to a mathematical model of the form (3), where $L=L(\Lambda)$ and $M=M(\Lambda)$ are polynomials with real coefficients. It is noted that the Barenblatt-Zheltov-Kochina equation for $\lambda \alpha \in \mathbb{R}_{+}$satisfies the sufficient conditions found, and therefore the initial-boundary value problem can have non-negative solutions. The final part of the article outlines directions for further possible research. The list of literature does not pretend to be complete and reflects only the tastes and preferences of the authors.

\section{Degenerate positive holomorphic groups of operators}

Let $U$ and $F$ be Banach spaces, operators $L \in \mathcal{L}(U ; F)$ (i.e. linear and continuous), $M \in C l(U ; F)$ (i.e. linear, closed and densely defined). Sets $\rho^{L}(M)=\left\{\mu \in \mathbb{C}:(\mu L-M)^{-1} \in \mathcal{L}(F ; \mho)\right\}$ and $\sigma^{L}(M)=C \backslash \rho^{L}(M)$ are called resolvent set and $L$-spectrum of operator $M$ respectively. Operator $M$ is $(L, \sigma)$-bounded if

$$
\exists a \in \mathbb{R}_{+} \forall \mu \in \mathbb{C} \quad(|\mu|>a) \Rightarrow\left(\mu \in \rho^{L}(M)\right) .
$$

If operator $M$ is $(L, 0)$-bounded, then operators $P, Q$ are the projectors

$$
P=\frac{1}{2 \pi i} \int_{\gamma} R_{\mu}^{L}(M) d \mu \in \mathcal{L}(\mathcal{U}), Q=\frac{1}{2 \pi i} \int_{\gamma} L_{\mu}^{L}(M) d \mu \in \mathcal{L}(F) .
$$

Here $R_{\mu}^{L}(M)=(\mu L-M)^{-1} L$ is called a right resolvent, and $L_{\mu}^{L}(M)=L(\mu L-M)^{-1}$ is is called a left resolvent of operator $M$; contour $\gamma=\{\mu \in \mathbb{C}:|\mu|=r>a\}$. Here and below, loop integrals are understood in the sense of Riemann. We consider subspaces $U^{0}=\operatorname{ker} P, V^{1}=\operatorname{im} P, F^{0}=\operatorname{ker} Q$, $F^{1}=\operatorname{im} Q ;$ and denote operator of the contraction $L(M)$ on $U^{k}\left(U^{k} \cap \operatorname{dom} M\right)$ by $L_{k}\left(M_{k}\right), k=0,1$.

Theorem 1.1. Let operator $M$ be $(L, \sigma)$-bounded. Then

(i) operators $L_{k} \in \mathcal{L}\left(V^{k} ; F^{k}\right), k=0,1$; and there exist the operator $L_{1}^{-1} \in \mathcal{L}\left(F^{1} ; V^{1}\right)$;

(ii) operators $M_{k} \in C l\left(U^{k} ; F^{k}\right), k=0,1$; and there exist the operator $M_{0}^{-1} \in \mathcal{L}\left(F^{0} ; \mathcal{U}^{0}\right)$.

Let operator $M b e(L, \sigma)$-bounded, construct the operator $H=M_{0}^{-1} L_{0} \in \mathcal{L}\left(\mathcal{U}^{0}\right)$. Operator $M$ is called $(L, p)$-bounded, $p \in \mathbb{N},((L, 0)$-bounded $)$ if $H^{p} \neq \mathbb{O}$, and $H^{p+1}=\mathbb{O}(H=\mathbb{O})$. Let operator $M$ be $(L, p)$-bounded, $p \in\{0\} \cup \mathbb{N}$, we consider the equation

$$
L \dot{u}=M u \text {. }
$$

Vector function $u=u(t), t \in \mathbb{R}$, is solution of equation (5) if it satisfies this equation. Decision $u=u(t)$ is called solution of the Cauchy problem

$$
u(0)=u_{0},
$$

if it satisfies condition (6) at some $u_{0} \in \mathcal{V}$. The set $\mathscr{P} \subset \mathcal{V}$ is phase space of equation (5) if its any solution $u(t) \in \mathcal{P}$ at each $t \in \mathbb{R}$; and for any $u_{0} \in \mathcal{P}$ there exists a unique solution $u \in C^{1}(\mathbb{R} ; \mathcal{U})$ of problem (6) for equation (5). Finally, we introduce a degenerate (if ker $L \neq\{0\}$ ) holomorphic (in the whole plane $\mathbb{C}$ ) group of operators 


$$
U^{t}=\frac{1}{2 \pi i} \int_{\gamma} R_{\mu}^{L}(M) e^{\mu t} d \mu, t \in \mathbb{C} .
$$

notice, that $V^{0}=P$, where $\operatorname{ker} P \supset \operatorname{ker} L$.

Theorem 1.2. Let operator $M$ be $(L, p)$-bounded, $p \in\{0\} \cup \mathbb{N}$. Then

(i) any solution $u \in C^{1}(\mathbb{R} ; \mathcal{V})$ of equation (5) has the form $u(t)=U^{t} u_{0}, t \in \mathbb{R}$, and some $u_{0} \in \mathcal{V}$;

(ii) the phase space of equation (5) is subspace $V^{1}$.

Thus, under the conditions of the theorem 1.2 $L$-resolvent $(\mu L-M)^{-1}$ of operator $M$ in the ring $|\mu|>a$ decomposes into a Laurent series

$$
(\mu L-M)^{-1}=\sum_{k=1}^{\infty} \mu^{-k} S^{k-1} L_{1}^{-1} Q-\sum_{k=0}^{p} \mu^{k} H^{k} M_{0}^{-1}(\mathbb{I}-Q),
$$

where operators $S=L_{1}^{-1} M_{1} \in \mathcal{L}\left(\mathcal{U}^{1}\right), H=M_{0}^{-1} L_{0} \in \mathcal{L}\left(\mathcal{U}^{0}\right)$. Hence the resolving degenerate group $U^{t}$ of equation (5) is as follows

where

$$
U^{t}=(\mathbb{I}-Q)+e^{S t} Q
$$

$$
e^{S t}=\frac{1}{2 \pi i} \int_{\gamma}(\mu \mathbb{I}-S) e^{\mu t} d \mu=\sum_{k=0}^{\infty} \frac{S t^{k}}{k !}
$$

is the group of operators of equation (5), given on the phase space $U^{1}$.

Next, we give an order relation " $\geq$ ", compatible with both vector and metric structures, to $U^{1}$. In other words, we assume that $\left(U^{1} ; \geq\right)$ is a Banach lattice. Recall those properties of Banach lattices, which will prove useful to us in the future. An arbitrary set $X$ is called ordered if on $X \times X$ there is the relation of order $\geq$, which satisfies the following axioms:

(io) $x \geq x$ for each $x \in X$;

(iio) $(x \geq y) \wedge(y \geq x) \Rightarrow(x=y)$ for any $x, y \in X$;

(iiio) $(x \geq y) \wedge(y \geq z) \Rightarrow(x \geq z)$ for any $x, y, z \in X$.

An ordered vector space $X$ is called Riesz space if in addition, the following axioms are satisfied:

(ivo) $(x \geq y) \Rightarrow(x+z \geq y+z)$ for all $x, y, z \in X$.

(vo) $(x \geq y) \Rightarrow(\alpha x \geq \alpha y)$ for all $x, y \in X$ and each $\alpha \in\{0\} \cup \mathbb{R}_{+}$.

The Riesz space $X$ is called functional Riesz space if $u \vee v, u \wedge v \in X$ for any $u, v \in X$. Here

$$
(u \vee v)(x)=\max (u(x), v(x)),(u \wedge v)(x)=\min \{u(x), v(x)\} .
$$

The spaces $C(\Omega), C(\bar{\Omega})$, where $\Omega \subset \mathbb{R}^{n}$ is a domain, and spaces $l_{q}$, where $q \in[1,+\infty]$ are the classical functional Riesz spaces examples. In these examples $u \vee v, u \wedge v$ are defined pointwise, but if measure is given on $\Omega$, and It is possible to define these elements almost everywhere, then the Lebesgue spaces $L_{q}(\Omega), q \in[1,+\infty]$ can be assigned to the to the functional Riesz spaces.

In the Riesz function space, the following elements can be defined $u_{+}=\max \{u, 0\}$, and $u_{-}=\min \{-u, 0\}$, so that $u=u_{+}-u_{-}$, and there is another element $|u|=u_{+}+u_{-}$. If norm $\|\cdot\|_{X}$ is given on the Riesz functional space $X$ and satisfies the axiom

(vio) $(|u| \geq|v|) \Rightarrow\left(\|u\|_{X} \geq\|v\|_{X}\right)$ for all $u, v \in X$,

then we call the Riesz function space $X$ normed Riesz function space. A complete normed functional space is called a Banach lattice. Spaces $C(\Omega), C(\bar{\Omega})$ and $L_{q}(\Omega)$ with the qualifications specified above, as well as space $l_{q}$, where domain $\Omega \subset \mathbb{R}^{n}, q \in[1,+\infty]$ are examples of Banach lattices.

Further, let $X$ is vector space. Convex set $C \subset X$ we call a cone if 


\section{Математика}

(ic) $C+C \subset C$;

(iic) $\alpha C \subset C$ for any $\alpha \in\{0\} \cup \mathbb{R}_{+}$;

(iiic) $C \cap(-C)=\{0\}$.

The cone $C$ is called generative if

(ivc) $C-C=X$.

Now let $X$ is Riesz space. We construct the set

$$
X_{+}=\{x \in X: x \geq 0\} .
$$

Proposal 1.1. Let $X$ be a vector space, $C \subset X$ is generative cone. Then $X$ is Riesz space, where relative $\geq$ is given by

$$
(x \geq y) \Leftrightarrow(x-y \in C) .
$$

Proposal 1.2. Let $X$ be Riesz space, then $X_{+}$is generative cone.

Let $X$ be Banach lattice with generative cone $X_{+}$. Linear bounded operator $A \in \mathcal{L}(X)$ is positive if $A u \geq 0$ for all $u \in X_{+}$. Holomorphic group of operators $X^{\cdot}=\left\{X^{t}: X^{t} \in \mathcal{L}(X)\right.$ for all $\left.t \in \mathbb{R}\right\}$ is called positive if $X^{t} u \geq 0$ for all $u \in X_{+}$and $t \in \mathbb{R}$.

Proposal 1.3. Holomorphic group $X^{\cdot}$ is called exactly positive when its generator is positive $A=\left(X^{t}\right)_{t=0}^{\prime}$.

Finally, let us return to the abstract problem (5), (6). We will be interested in its positive solution $u=u(t)$, i.e. such that $u(t) \geq 0$ for all $t \in \mathbb{R}$. Therefore, we consider the phase space of equation (5) $v^{l}$ Banach lattice, generated by a cone $V_{+}^{1}$. $(L, p)$-bounded operator $M$ is positive $(L, p)$-bounded, $p \in\{0\} \cup \mathbb{N}$ if $S u \in \mathcal{U}_{+}^{1}$ for any $u \in \mathcal{V}_{+}^{1}$. The degenerate holomorphic group $U^{\bullet} \in C^{\infty}(\mathbb{R} ; \mathcal{L}(\mathcal{U}))$, generated $(L, p)$-by positive operator $M$ is called a degenerate positive holomorphic group.

Theorem 1.3. Let operator $M$ is positive $(L, p)$-bounded, $p \in\{0\} \cup \mathbb{N}$. Then for any $u_{0} \in V_{+}^{1}$ there is the unique positive solution $u=u(t), t \in \mathbb{R}$, of problem (5), (6), and it has the form $u(t)=S^{t} u_{0}$.

\section{Mathematical model in sequence spaces}

Let $U$ и $F$ be Banach spaces, operators $L \in \mathcal{L}(U ; F), M \in C l(U ; F)$, and operator $M$ is $(L, p)$ bounded, $p \in\{0\} \cup \mathbb{N}$. Consider a linear inhomogeneous equation of Sobolev type

$$
L \dot{u}=M u+f .
$$

Vector function $u \in C([0, \tau) ; \vartheta) \cap C^{1}((0, \tau) ; \vartheta), \tau \in \mathbb{R}_{+}$, is called solution of equation (7) if it satisfies this equation for some $f=f(t)$. The solution $u=u(t)$ of equation (7) is called solution of the Showalter-Sidorov problem [9]

$$
\lim _{t \rightarrow 0+} P\left(u(t)-u_{0}\right)=0,
$$

if it also satisfies the initial condition (8). Here $P: U \rightarrow V^{l}$ along $V^{0}$ is projector. Further, let $v$ be a Banach lattice generated by the cone $V_{+}$. The solution $u=u(t)$ of problem (7), (8) is positive if $u(t) \in V_{+}$for any $t \in[0, \tau)$.

We will be interested in the conditions under which the solution $u=u(t)$ of problem (7), (8) is positive. Let $F$ be also be a Banach lattice generated by a cone $F_{+}$. If operator $M$ is $(L, p)$-bounded, $p \in\{0\} \cup \mathbb{N}$, then it is not difficult to show that the subspaces $\mho^{k}$ and $F^{k}, k=0,1$, are also Banach lattices generated by cones $V_{+}^{k}=V^{k} \cap V_{+}$and $F_{+}^{k}=F^{k} \cap F_{+}, k=0,1$, respectively. $(L, p)$-bounded operator $M$ is called strongly positive if 
(ip) operator $L_{0}: V_{+}^{0} \rightarrow F_{+}^{0}$, and operator $L_{1}: U_{+}^{1} \rightarrow F_{+}^{1}$ is a toplinear isomorphism;

(iip) operator $M_{1}: \mathcal{V}_{+}^{1} \cap \operatorname{dom} M \rightarrow F_{+}^{1}$ and operator $M_{0}: \mathcal{V}_{+}^{0} \cap \operatorname{dom} M \rightarrow F_{+}^{0}$, and $M_{0}^{-1}\left[F_{+}^{0}\right] \subset V_{+}^{0}$.

It is easy to see that strongly positive $(L, p)$-bounded operator $M$ is positive $(L, p)$-bounded , $p \in\{0\} \cup \mathbb{N}$. Let be $f=(\mathbb{I}-Q) f+Q f=f^{0}+f^{1}$, where $Q: F \rightarrow F^{1}$ is projector along $F_{0}$.

Theorem 2.1. Let $V$ be a Banach lattice and operator $M$ is strongly positive $(L, p)$-bounded, $p \in\{0\} \cup \mathbb{N}$. Then for any vector functions $f:[0, \tau) \rightarrow F$ such that $f^{0} \in C^{p+1}\left((0, \tau) ; F^{0}\right),-f^{0(k)}(t) \in F_{+}^{0}, k=\overline{0, p+1}, \quad t \in(0, \tau), \quad f^{1} \in C\left([0, \tau) ; F_{+}^{1}\right)$, and for any vector $u_{0} \in \mathcal{V}$, such that $u_{0}^{1} \in \mathcal{V}_{+}^{1}$ there exists the unique positive solution $u=u(t)$, which also has the form

$$
u(t)=-\sum_{k=0}^{p} H^{k} M_{0}^{-1} f^{0(k)}(t)+U^{t} u_{0}+\int_{0}^{\tau} U^{t-\tau} L_{1}^{-1} f^{1}(\tau) d \tau .
$$

Here $f^{0(k)}(t)=\frac{d^{k}}{d t^{k}} f^{0}(t), k=\overline{0, p+1}$. Proof of the theorem 2.1 does not differ fundamentally from the proof of the theorem 5.1.1 [5]. We check the positivity of the resulting solution for the reader. We also note that condition $-f^{0(k)}(t) \in F_{+}^{0}, t \in(0, \tau), k=\overline{0, p+1}$, seems difficult, so here is an example: $f^{0}(t)=-e^{\alpha t} f^{0}$, where $\alpha \in \mathbb{R}_{+}, f_{0} \in F_{+}^{0}$.

We consider Sobolev sequence spaces $l_{q}^{m}, m \in \mathbb{R}, q \in[1,+\infty)$. First of all, we note that these spaces are Banach spaces with the norm

$$
\|u\|_{m, q}=\left(\sum_{k=1}^{\infty} \lambda_{k}^{\frac{m q}{2}}\left|u_{k}\right|^{q}\right)^{\frac{1}{q}} .
$$

Then pay attention to dense and continuous investments $l_{q}^{m} \hookrightarrow l_{q}^{n}$ at $m \geq n$. (The proof of this fact is left to the reader). Finally, we set operator $\Lambda u=\left(\lambda_{k} u_{k}\right)$, where $u=\left(u_{k}\right)$. We show that operator $\Lambda \in \mathcal{L}\left(l_{q}^{m+2} ; l_{q}^{m}\right)$. Indeed,

$$
\|\Lambda u\|_{m, q}=\left(\sum_{k=1}^{\infty} \lambda_{k}^{\frac{m q}{2}+q}\left|u_{k}\right|^{q}\right)^{\frac{1}{q}}=\|u\|_{m+2, q} .
$$

Let's construct operators $L=L(\Lambda)$ and $M=M(\Lambda)$, where $L(s)$ and $M(s)$ are polynomials with real (for simplicity) coefficients. If the condition (4) is satisfied, that operators $L, M \in \mathcal{L}\left(l_{q}^{m+\operatorname{deg} L} ; l_{q}^{m}\right)$, $m \in \mathbb{R}, q \in[1,+\infty)$. Indeed, $\|u\|_{m+\operatorname{deg} L, q} \geq\|u\|_{m+\operatorname{deg} M, q}, u \in l_{q}^{m+\operatorname{deg} L}, m \in \mathbb{R}, q \in[1,+\infty)$. Hence, by the continuity of the embedding $l_{q}^{m+\operatorname{deg} L} \hookrightarrow l_{q}^{m+\operatorname{deg} M}$ follows the truth of what has been said.

Lemma 2.1. Let

(i) the condition (4) is satisfied;

(ii) polynomials $L=L(s)$ and $M=M(s)$ have only real roots and have no common roots.

Then operator $M$ is $(L, 0)$-bounded.

Before proceeding with the proof of this assertion, we make a number of remarks. At first, let operators $L, M \in \mathcal{L}(U ; F)$, where $V$ and $F$ are Banach spaces. If there exists a vector $\psi \in \mathcal{V}$ such that $M \psi=L \varphi$, where the vector $\varphi \in \operatorname{ker} L \backslash\{0\}$, then it is called the adjoint vector of operator $L$. Secondly, operator $A \in \mathcal{L}(U ; F)$ is called Fredholm operator, if $\operatorname{dim} \operatorname{ker} A=\operatorname{codim} \operatorname{im} A$. Third, the proof of Lemma 2.1 will be based on the following assertion, which is a particular case of Theorem 4.6.1 [5]. 


\section{Математика}

Proposal 2.1. Let be operators $L, M \in \mathcal{L}(U ; F)$, and operator $L$ is Fredholm operator. Then the following statements are equivalent:

(i) operator $M$ is $(L, 0)$-bounded;

(ii) operator $L$ does not have associated vectors.

We proceed to the proof of the lemma 2.1. Fredholmism of operator $L=L(\Lambda)$ is obvious. Let polynomial $L=L(s)$ has no real roots. Then $\operatorname{ker} L(\Lambda)=\{0\}$, means operator $L$ does not have associated vectors. If polynomial $L=L(s)$ has real roots, then $\operatorname{ker} L(\Lambda) \neq\{0\}$ and finite-dimensional. If condition (ii) of the lemma 2.1 is satisfied, then $M(\Lambda) \varphi \notin \operatorname{im} L(\Lambda)$ for all $\varphi \in \operatorname{ker} L(\Lambda) \backslash\{0\}$. Lemma 2.1 is proved.

We introduce in spaces $l_{q}^{m}, m \in \mathbb{R}, q \in[1,+\infty)$, Banach lattices. In each of them we choose a family of vectors $\left\{e_{k}\right\}$, all components of which are zero except for the component that is equal to unity. We construct the linear span of these families consisting of linear combinations of these vectors with positive coefficients. The closure of this linear shell in the norm of the space $l_{q}^{m}$ we denote by $C_{q}^{m}$, $m \in \mathbb{R}, q \in[1,+\infty)$. As is easy to see, $C_{q}^{m}$ is generating cone in space $l_{q}^{m}, m \in \mathbb{R}, q \in[1,+\infty)$.

Lemma 2.2. Let the conditions of the lemma 2.1 are satisfied, and all the coefficients of the polynomials $L(s)$ and $M(s)$ are positive. Then operator $M$ is strongly positive $(L, 0)$-bounded.

Proof. By the lemma 2.1 and theorem 1.1 space $l_{q}^{m+\operatorname{deg} L}$ splits into a direct sum $l_{q, 0}^{m+\operatorname{deg} L} \oplus l_{q, 1}^{m+\operatorname{deg} L}$, and $l_{q, 0}^{m+\operatorname{deg} L}=\operatorname{ker} L(\Lambda)$. If $\operatorname{ker} L(\Lambda)=\{0\}$, then the assertion of Lemma 2.2 is obvious. Let $\operatorname{ker} L(\Lambda) \neq\{0\}$. This can happen only when one of the roots of the polynomial $L(s)$ coincides with a member of the sequence $\left\{\lambda_{k}\right\}$. By construction, the sequence $\left\{\lambda_{k}\right\}$ monotonically increases, and $\lim _{k \rightarrow \infty} \lambda_{k}=+\infty$. This, in particular, means that a set of equal terms of a sequence can not be infinite. Let $\lambda_{j}=\lambda_{j+l}=\ldots=\lambda_{j+l}=\lambda$, where $\lambda$ is the root of the polynomial $L(s)$. Hence $\operatorname{ker} L(\Lambda)=\operatorname{span}\left\{e_{j}, e_{j+1}, \ldots, e_{j+l}\right\}$.

Further, the space $l_{q}^{m}$ also splits into a direct sum $l_{q, 0}^{m} \oplus l_{q, 1}^{m}$, and $l_{q, 0}^{m}=M(\Lambda)[\operatorname{ker}(\Lambda)]=\operatorname{span}\left\{e_{j}, e_{j+1}, \ldots, e_{j+l}\right\}$, a $l_{q, 1}^{m}=\operatorname{im} L(\Lambda)$, i.e. $l_{q, 1}^{m}$ there is a closure in the norm $l_{q, 1}^{m}$ span of vectors $\left\{e_{k}: \lambda_{k} \neq \lambda\right\}$.

Hence, $l_{q, 1}^{m+\operatorname{deg} L}$ there is a closure $\operatorname{span}\left\{e_{k}: \lambda_{k} \neq \lambda\right\}$ in norm $l_{q, 1}^{m+\operatorname{deg} L}$. Strongly positive $(L, 0)$ limitation of operator $M$ follows from the positivity of the coefficients of the polynomials $L(s)$ and $M(s)$.

By Lemmas 2.1, 2.2 and Theorem 2.1, we have

Theorem 2.2. Let the conditions of Lemmas 2.1 and 2.2. Then for any vector function $f=f(t)$ such that $f^{0} \in C^{1}\left((0, \tau) ; l_{q, 0}^{m+\operatorname{deg} L}\right) \quad$ and $\quad-f^{0}(t) \in C_{q}^{m+\operatorname{deg} L} \cap l_{q, 0}^{m+\operatorname{deg} L} ; t \in(0, \tau)$, and $f_{1} \in C\left([0, \tau) ; C_{q}^{m+\operatorname{deg} L} \cap l_{q, 1}^{m+\operatorname{deg} L}\right)$ and any vector $u_{0} \in C_{q}^{m+\operatorname{deg} L}$, such that $u_{0}^{1} \in C_{q}^{m+\operatorname{deg} L} \cap l_{q, 1}^{m+\operatorname{deg} L}$, there exists a unique positive solution of the problem (7), (8) $u=u(t)$, which also has the following form

$$
u(t)=-M_{0}^{-1} f^{0}(t)+U^{t} u_{0}+\int_{0}^{t} U^{t-s} L_{1}^{-1} f^{1}(s) d s .
$$

Here 


$$
M_{0}^{-1} f^{0}(t)=\sum_{\lambda=\lambda_{k}} \frac{f_{k}(t) e_{k}}{M\left(\lambda_{k}\right)}, U^{t} u_{0}=\sum_{k=1}^{\infty}{ }^{\prime} \exp \left(\frac{M\left(\lambda_{k}\right)}{L\left(\lambda_{k}\right)} t\right) u_{0 k} e_{k}, L_{1}^{-1} f^{1}(t)=\sum_{k=1}^{\infty}, \frac{f_{k}(t) e_{k}}{L\left(\lambda_{k}\right)},
$$

and the prime at the sum sign means that the summation is over the set $\left\{k \in \mathbb{N}: \lambda_{k} \neq \lambda\right\}$.

Comment 2.1. All the arguments above were carried out under the implicit assumption that only one root of the polynomial $L(s)$ coincides with some term of the sequence $\left\{\lambda_{k}\right\}$. However, these arguments are not difficult to extend to the case when several roots and even all the roots of the polynomial $L(s)$ coincide with the terms of the sequence $\left\{\lambda_{k}\right\}$.

Comment 2.2. If we return to the mathematical models (1) and (2) and consider them from the point of view of the approach suggested above, then we can see that in the case (1), non-negative solutions are possible (at $\lambda, \alpha \in \mathbb{R}_{+}$), and in the case of (2) such decisions can not be made (even with $f(t) \equiv 0)$.

\section{Conclusion}

To continue the tradition laid down in [7], the next step should be the study of a stochastic model of the form (3). To date, the main results have already been obtained, but unlike [7] they are based not on the Ito-Stratonovich-Skorokhod approach, but on the Nelson-Glickich derivative [9]. In addition, it would be interesting to consider various generalizations of the Showalter-Sidorov condition [10]. Finally, it would be nice to consider the relations between the powers of the polynomials $L$ and $M$, other than (4) [11-13].

The work was supported by Act 211 Government of the Russian Federation, contract № 02.A03.21.0011.

\section{References}

1. Barenblatt G.I., Zheltov Iu.P., Kochina I.N. Basic concepts in the theory of seepage of homogeneous liquids in fissured rocks [strata]. Journal of Applied Mathematics and Mechanics, 1960, Vol. 24, Issue 5, pp. 1286-1303. DOI: 10.1016/0021-8928(60)90107-6

2. Hallaire M. Soil water movement in the film and vapor phase under the influence of evapotranspiration. Water and its conduction insoils. Proceedings of XXXVII Annual Meeting of the Highway Research Board, Highway Research Board Special Report, 1958, Vol. 40, pp. 88-105.

3. Chen P.J., Gurtin M.E. On a theory of heat conduction involving two temperatures. Journal of Applied Mathematics and Physics (ZAMP), 1968, Vol. 19, Issue 4, pp. 614-627. DOI: 10.1007/BF01594969

4. Hoff N.J. Creep buckling. The Aeronautical Quarterly, 1956, Vol. 7, no. 1, pp. 1-20.

5. Sviridyuk G.A., Fedorov V.E. Linear Sobolev type equations and degenerate semigroups of operators. VSP, Utrecht-Boston-Köln-Tokyo, 2003, 216 p. DOI: 10.1515/9783110915501

6. Banasiak J., Arlotti L. Perturbations of Positive Semigroups with Applications, Springer-Verlag, London Limited, 2006, 438 p. DOI: 10.1007/1-84628-153-9

7. Chekroun M.D., Park E. Temam R. The Stampacchia maximum principle for stochastic partial equations and applications. Journal of Differential Equations, 2016, Vol. 260, Issue 3, pp. 2926-2972. DOI: $10.1016 /$ j.jde.2015.10.022

8. Sviridyuk G.A., Zagrebina S.A. The Showalter-Sidorov problem as a phenomena of the Sobolevtype equations. Izvestiya Irkutskogo Gosudarstvennogo Universiteta. Seriya "Matematika", Vol. 3, Issue 1, pp. 104-125. (in Russ.).

9. Sviridyuk G.A., Manakova N.A. Dynamic models of Sobolev type with the Showalter-Sidorov condition and additive "noises". Bulletin of the South Ural State University. Series "Mathematical Modelling, Programming \& Computer Software", 2014, Vol. 7, no. 1, pp. 90-103. (in Russ.). DOI: $10.14529 / \mathrm{mmp} 140108$

10. Zagrebina S.A. A multipoint initial-final value problem for a linear model of plane-parallel thermal convection in viscoelastic incompressible fluid. Bulletin of the South Ural State University. Series "Mathematical Modelling, Programming \& Computer Software", 2014, Vol. 7, no. 3, pp. 5-22. DOI: $10.14529 / \mathrm{mmp} 140301$ 


\title{
Математика
}

11. Favini A., Sviridyuk G.A., Manakova N.A. Linear Sobolev Type Equations with Relatively pSectorial Operators in Space of "noises". Abstract and Applied Analysis, 2015, Vol. 2015, Article ID 697410. DOI: 10.1155/2015/697410

12. Favini A., Sviridyuk G.A., Sagadeeva M.A. Linear Sobolev type equations with relatively pradial operators in space of "noises". Mediterranian Journal of Mathematics, 2016, Vol. 13, no. 6, pp. 4607-4621. DOI 10.1007/s00009-016-0765-x

13. Favini A., Sviridyuk G.A., Zamyshlyaeva A.A. One class of Sobolev type equations of higher order with additive "white noise". Communications on Pure and Applied Analysis, 2016, Vol. 15, no. 1, pp. 185-196. DOI:10.3934/cpaa.2016.15.185

Received September 23, 2017

Bulletin of the South Ural State University Series "Mathematics. Mechanics. Physics" 2017, vol. 9, no. 4, pp. 27-35

\section{УДК 517.9}

DOI: 10.14529/mmph170404

\section{НЕКОТОРЫЕ МАТЕМАТИЧЕСКИЕ МОДЕЛИ СОБОЛЕВСКОГО ТИПА С ОТНОСИТЕЛЬНО ПОЗИТИВНЫМИ ОПЕРАТОРАМИ В ПРОСТРАНСТВАХ ПОСЛЕДОВАТЕЛЬНОСТЕЙ}

\author{
Н.Н. Соловьёва, С.А. Загребина, Г.А. Свиридюк \\ Южно-Уральский государственный университет, г. Челябинск, Российская Федерация \\ E-mail: zargebinasa@susu.ru
}

В пространствах последовательностей, являющихся аналогами функциональных пространств Соболева, рассмотрена математическая модель, прототипами которой служат уравнение Баренблатта-Желтова-Кочиной и уравнение Хоффа. Отметим, что эти уравнения являются вырожденными уравнениями или уравнениями соболевского типа. Для таких уравнений отличительной чертой служат феномены несуществования и неединственности решений. Поэтому нахождение условий существования позитивных решений таких уравнений - актуальное направление исследований. В статье описаны условия, достаточные для существования позитивных решений в рассмотренной математической модели. Фундаментом наших исследований стали теория позитивных полугрупп операторов и теория вырожденных голоморфных групп операторов. В результате слияния этих теорий получилась новая теория вырожденных позитивных голоморфных групп операторов. Авторы надеются, что результаты новой теории найдут применение в экономических и инженерных задачах.

Ключевые слова: соболевы пространства последовательностей; модели соболевского типа; вырожденные позитивные голоморфные группы операторов.

\section{Литература}

1. Баренблатт, Г.И. Об основных представлениях теории фильтрации однородных жидкостей в трещиноватых породах / Г.И. Баренблатт, Ю.П. Желтов, И.Н. Кочина // Прикладная математика и механика. - 1960. - Т. 24, № 5. - С. 58-73.

2. Hallaire, M. Soil water movement in the film and vapor phase under the influence of evapotranspiration. Water and its conduction insoils / M. Hallaire // Proceedings of XXXVII Annual Meeting of the Highway Research Board, Highway Research Board Special Report. - 1958. - Vol. 40. - P. 88-105.

3. Chen, P.J. On a Theory of Heat Conduction Involving Two Temperatures / P.J. Chen, M.E. Gurtin // Journal of Applied Mathematics and Physics (ZAMP). - 1968. - Vol. 19, Issue 4. - P. 614-627.

4. Hoff, N.J. Creep buckling / N.J. Hoff // The Aeronautical Quarterly. - 1956. -Vol. 7, no. 1. P. 1-20.

5. Sviridyuk, G.A. Linear Sobolev Type Equations and Degenerate Semigroups of Operators / G.A. Sviridyuk, V.E. Fedorov. - Utrecht; Boston; Köln; Tokyo: VSP, 2003. - 216 p. 
6. Banasiak, J. Perturbations of Positive Semigroups with Applications / J. Banasiak, L. Arlotti. Springer-Verlag, London Limited, 2006. - 438 p.

7. Chekroun, M.D. The Stampacchia maximum principle for stochastic partial equations and applications / M.D. Chekroun, E. Park, R. Temam // Journal of Differential Equations. - 2016. - Vol. 260, Issue 3. - P. 2926-2972.

8. Свиридюк, Г.А. Задача Шоуолтера - Сидорова как феномен уравнений соболевского типа / Г.А. Свиридюк, С.А. Загребина // Известия Иркутского государственного университета. Серия «Математика». - 2010. - Т. 3, № 1. - С. 104-125.

9. Свиридюк, Г.А. Динамические модели соболевского типа с условием ШоуолтераСидорова и аддитивными «шумами» / Г.А. Свиридюк, Н.А. Манакова // Вестник ЮжноУральского государственного университета. Серия «Математическое моделирование и программирование». - 2014. - Т. 7, № 1. - С. 90-103.

10. Zagrebina, S.A. A multipoint initial-final value problem for a linear model of plane-parallel thermal convection in viscoelastic incompressible fluid / S.A. Zagrebina // Вестник Южно-Уральского государственного университета. Серия «Математическое моделирование и программирование». 2014. - T. 7, № 3. - C. 5-22.

11. Favini, A. Linear Sobolev Type Equations with Relatively p-Sectorial Operators in Space of "noises" / A. Favini, G.A. Sviridyuk, N.A. Manakova // Abstract and Applied Analysis. - 2015. Vol. 2015. - Article ID 697410.

12. Favini, A. Linear Sobolev type equations with relatively p-radial operators in space of "noises" / A. Favini, G.A. Sviridyuk, M.A. Sagadeeva // Mediterranian Journal of Mathematics. - 2016. - Vol. 13, no. 6. - P. 4607-4621.

13. Favini, A. One class of Sobolev type equations of higher order with additive "white noise" / A. Favini, G.A. Sviridyuk, A.A. Zamyshlyaeva // Communications on Pure and Applied Analysis. 2016. - Vol. 15, no. 1. - P. 185-196.

Поступила в редакцию 23 сентября 2017 z. 